\title{
Pattern of anemia in geriatric patients- A hospital based prospective study
}

\author{
Singh $\mathbf{R}^{1}$, Gaur B. $\mathbf{S}^{2}$ \\ ${ }^{1}$ Dr. Roma Singh, Assistant Professor, Department of Pathology, ${ }^{2}$ Dr. Bindu Singh Gaur, Associate Professor, \\ Department of Pathology. All authors are affiliated with L. N. Medical College and Research Centre and associated J.K \\ Hospital Bhopal, (M.P) India.
}

Address for Correspondence: Dr. Roma Singh, Email i.d -dr.roma16@gmail.com

\begin{abstract}
Introduction: Anaemia is common in elderly age group and is overlooked as the symptoms such as fatigue, weakness, shortness of breath may be attributed to the ageing process itself but decline in the haematological parameter with age is not necessarily as a result of normal aging. Low $\mathrm{Hb}$ is a powerful prognostic marker for multiple adverse outcomes in the elderly. Clinicians should be alerted to the increased risk of morbidity, hospitalization and mortality in the elderly associated with anemia. Aim of study: To evaluate the prevalence of geriatric anaemia, morphological pattern of geriatric anaemia and to find its commonest morphological pattern amongst the geriatrics in hospitalized patients. Material and Methods: A hospital based observational prospective study of 6 months from August 2015 to January 2016 conducted in haematology section of Pathology department at L. N. Medical college and RC and attached J. K. Hospital Bhopal, M.P. in which 200 hospitalized geriatric patients both male and female above the age of 60 years were included and were evaluated for the prevalence of anemia in both the genders along with morphological pattern of anemia. Results: Prevalence of anemia in geriatrics including both sexes is $69 \%(\mathrm{n}=138 / 200)$. In female group $73.68 \%$ (56/76) and in Male group there were 66.12\% (82/124) anaemic cases. Most common morphological pattern is normocytic normochromic anaemia i.e $37.68 \%$. Conclusion: Study of various morphological patterns of anaemia helps in guiding aetiology of anaemia and thus directing towards the further required investigations facilitating the choice and implementation of effective therapy.
\end{abstract}

Key words-Anaemia, Geriatrics, Morbidity, Pattern.

\section{Introduction}

Whether anemia is marker or mediator of disease is not always clear but it is usually a signal of pathology and is associated with increased morbidity and mortality. Anaemia is common in elderly age group and is overlooked as the symptoms such as fatigue, weakness, shortness of breath may be attributed to the ageing process itself but decline in the haematological parameter with age is not necessarily as a result of normal aging $[1,2]$. The number of elderly globally is projected to grow from about 524 million in 2010 to nearly 1500 million in 2050 [3].

Many studies indicate that as the age advances prevalence of anemia also increases and it is more

Manuscript received $15^{\text {th }}$ May 2016

Reviewed: $26^{\text {th }}$ May 2016

Author Corrected: $10^{\text {th }}$ June 2016

Accepted for Publication $21^{\text {st }}$ June 2016 common in elderly female [3]. The prevalence of anaemia increases with advancing age [4]. This ranges between $8-44 \%$ worldwide with highest prevalence in men 85 years and older [5]. In Indian population the prevalence varies between $6 \%$ and $30 \%$ among males and $10 \%$ and $20 \%$ among females [6].

Despite of high prevalence of anemia in elderly only a few studies have focused on affect of anaemia on the overall outcome of elderly patient.

According to the world health organization, there are two billion people with anemia in the world and half of the anemia is due to iron deficiency [7]. Anemia is a common condition in elderly especially in hospitalized geriatric patients and is known to be associated with 
increased morbidity and mortality [8]. Hospitalised patients are at a higher risk of developing anemia [9].

Anemia in the elderly can generally be categorized into four major types: anemia related to nutrient deficiencies (iron, cobalamin and folic acid), anemia related to chronic inflammation, anemia due to renal insufficiency, and unexplained anemia [10].

Low $\mathrm{Hb}$ is a powerful prognostic marker for multiple adverse outcomes in the elderly. Clinicians should be alerted to the increased risk of morbidity, hospitilization and mortality in the elderly associated with anemia.

A hematological profile is the first and most common investigation undertaken for any patient in a hospital.

This. study was conducted to evaluate the prevalence of geriatric anaemia, morphological pattern of geriatric anaemia and to find its commonest morphological pattern amongst the geriatrics in hospitalized patients.

Study of various morphological pattern of anemia helps in guiding etiology of anemia and thus directing towards the further required investigations.

\section{Materials and Methods}

A hospital based observational prospective study of 6 months from August 2015 to January 2016 conducted in hematology section of pathology department at L. N. Medical College and attached J. K. Hospital Bhopal, M.P. in which 200 hospitalized geriatric patients both male and female above the age of 60 years were included and were evaluated for the prevalence of anemia in both the genders along with morphological pattern of anemia based on RBC indices and peripheral smear.

Anemic patients were diagnosed according to the WHO criteria of anemia $\mathrm{Hb}<13 \mathrm{gm} \%$ in males and $\mathrm{Hb}$ $<12 \mathrm{gm} \%$ in females (11).

Elderly were defined as a person 60 years and above according to WHO criteria. Anemia was further graded into mild, moderate and severe according to WHO criteria as [12]: Mild anemia was defined as Hb-11-12.9 $\mathrm{g} / \mathrm{dl}$ in males, $11-11.9 \mathrm{~g} / \mathrm{dl}$ in females.

Moderate anemia was defined as-Hb 8-10.9 g/dl and severe anemia- $\mathrm{Hb}<8 \mathrm{~g} / \mathrm{dl}$. Based on the morphological types, microcytic anaemia were classified in which MCV was below $80 \mathrm{ft}$, macrocytic anaemia in which MCV was $>100 \mathrm{ft}$ and normocytic anaemia in which MCV was between 80-100 ft (13).

Dimorphic anemia was diagnosed when $\mathrm{M} \mathrm{CV}$ was normal but RDW is more than normal (Normal $=11$ $15 \%$ ) and confirmed by peripheral smear. Blood sample were collected in the EDTA tube and tests performed for haemoglobin and $\mathrm{RBC}$ indices using automated Nihon kohden blood cell counter in hematology lab.

In our study we chose to include all geriatric patients admitted to our hospital, independent of grounds for hospitalization.

\section{Results}

Table -1: Age and sex distribution of all patients included in the study.

\begin{tabular}{|c|c|c|c|}
\hline Age Groups & Female & Male & Total \\
\hline $61-65$ years & $50(25 \%)$ & $68(34 \%)$ & $120(60 \%)$ \\
\hline $66--70$ years & $12(06 \%)$ & $30(15 \%)$ & $20(10 \%)$ \\
\hline $71-75$ years & $06(03 \%)$ & $14(07 \%)$ & $08(04 \%)$ \\
\hline $76-80$ years & $04(02 \%)$ & $04(02 \%)$ & $02(01 \%)$ \\
\hline $81-85$ years & $02(01 \%)$ & $04(02 \%)$ & $06(03 \%)$ \\
\hline $86-90$ years & $02(01 \%)$ & $\mathbf{1 2 4}(\mathbf{6 2 \%})$ & $\mathbf{2 0 0}$ \\
\hline Total & $\mathbf{7 6 ( 3 8 \% )}$ & \\
\hline
\end{tabular}

Total number of cases included in the study $=200$. Male $62 \%(124)$, Female $38 \%$ (76), Maximum number $(60 \%)$ of cases are in the group of 61-65years. 
Table No.-2: Distribution of Anemic patients according to their age and sex.

\begin{tabular}{|c|c|c|c|}
\hline Age Groups & Female & Male & Total \\
\hline $61-65$ years & 34 of $50(68 \%)$ & 42 of $68(61.76 \%)$ & 76 of $118(64.40 \%)$ \\
\hline $66-70$ years & 10 of $12(83.33 \%)$ & 20 of $30(66.66 \%)$ & 30 of $42(71.42 \%)$ \\
\hline 71-75years & 05 of $06(83.33 \%)$ & 10 of $14(71.42 \%)$ & 15 of $20(75 \%)$ \\
\hline 76-80years & 03 of $04(75 \%)$ & 03 of $04(75 \%)$ & 06 of $08(75 \%)$ \\
\hline $81-85$ years & 02 of $02(100 \%)$ & 03 of $04(75 \%)$ & 05 of $06(83.33 \%)$ \\
\hline $86-90$ years & 02 of $02(100 \%)$ & 04 of $04(100 \%)$ & 06 of $06(100 \%)$ \\
\hline Total & 56 of $76(73.68 \%)$ & 82 of $124(66.12 \%)$ & 138 of $200(69 \%)$ \\
\hline
\end{tabular}

Prevalence of anemia in geriatrics including both sexes is 69\% $(\mathrm{n}=138)$.In female group 73.68\% (56/76) and in Male group there were $66.12 \%(82 / 124)$ anaemic cases. Most affected age groups of anemic patients including both sexes is 81 -90 years with prevalence of anemia ranging $83-100 \%$.

Table No.-3: Distribution of morphological pattern of anemia.

\begin{tabular}{|c|c|c|c|}
\hline Morphological pattern of Anemia & Female & Male & Total \\
\hline Normocytic Normochromic & $22(39.29 \%)$ & $30(36.58 \%)$ & $52(37.68 \%)$ \\
\hline Normocytic Hypochromic & $04(7.14 \%)$ & $20(24.39 \%)$ & $24(17.39 \%)$ \\
\hline Microcytic Hypochromic & $26(46.43 \%)$ & $18(21.95 \%)$ & $44(31.88 \%)$ \\
\hline Macrocytic & $02(3.57 \%)$ & $04(4.88 \%)$ & $06(4.35 \%)$ \\
\hline Dimorphic & $02(3.57 \%)$ & $10(12.20 \%)$ & $12(8.70 \%)$ \\
\hline $\begin{array}{c}\text { Total number of anemic } \\
\text { patients/total number of patients }\end{array}$ & $56 / 76$ & $82 / 124$ & $138 / 200$ \\
\hline
\end{tabular}

Most common morphological pattern is normocytic normochromic anemia i.e $37.68 \%$ followed by microcytic hypochromic anemia i.e $31.88 \%$ of total anaemic patients including both sexes.

In the female anemic group most common pattern is microcytic hypochromic anemia i.e $46.43 \%$ and in Male anemic group most common pattern is normocytic normochromic anemia i.e $36.58 \%$

Table No.-4: Distribution of degree of Anemia in both female and male group

\begin{tabular}{|c|c|}
\hline Grades of anemia & Total (males and females) \\
\hline Mild Anemia & $93(67.39 \%)$ \\
\hline Moderate Anemia & $21(15.22 \%)$ \\
\hline Severe Anemia & $24(17.39 \%)$ \\
\hline Total anemic patients & 138 \\
\hline
\end{tabular}

Mild degree of anemia is present in most $67.39 \%,(n=93)$ of cases including both sexes

\section{Discussion}

It is easy to overlook anaemia in elderly since symptoms such as fatigue, weakness and shortness of breath may be attributed to the aging process itself, but the decline of haemoglobin and concomitant increased degree of anaemia with age is not necessary a result of normal aging $[2,3]$. Anemia is a common condition in elderly especially in hospitalized geriatric patients and is known to be associated with increased morbidity and mortality [8] Hospitalised patients are at a higher risk of developing anemia [9]. 
Present study included elderly patients ageing from 6090 years.

In our study prevalence of anemia including both sexes is $69 \%(138 / 200)$.

- S.Amarneel etal [14] in a study noted that prevalence of anemia was $52.5 \%$.

- Similarly Saurabh R. Srivastava [15] also noted that the prevalence of anemia in elderly population was $68.5 \%$.

Our study shows that prevelance of anemia increases with advancing age.

- Ferrucci L, also noted similar results [4].

Using World health organization criteria the prevalence of anemia is found to range from 8-44 \% with highest prevalence in men 85 years and older [5].

In our study out of 200 cases 138 patients were found to be anemic which included $56 / 76$ females and $82 / 124$ males.

In our study prevalence of anemia is more in females $(73.68 \%)$.

- This was in correlation with Sourabh R Shrivastava et al study which also noted prevalence of anemia more in females [15].

- This differs from National Health and Nutrition Examination Survey (NHANES- III) carried out in United States which revealed prevalence of anemia is $11 \%$ in males and $10.2 \%$ in females in people ageing 65 and above [16].

This contradiction could be due to hospital based study in comparison to population based study of NHANESIII Discrepancy may be accountable to the fact that in contrast to the current study with its population of hospitalized elderly patients and most other studies have examined ambulant patients or older people in the community $[17,18]$.

Anemia in most cases was found to be mild $67.3 \%$ $(\mathrm{n}=93)$ with $\mathrm{Hb}$ level $>10 \mathrm{gm} / \mathrm{dl}$ in accordance with previously published results [18, 19]. However, even mild anaemia is frequently associated with negative outcome with regard to mortality and morbidity in the elderly [20] and should therefore not be accepted as a normal physiological response to the aging process.
In our study, morphological pattern of anaemia was established by RBC indices and confirmed by peripheral smear.

The present study highlighted that normocytic normochromic was the commonest morphological pattern of anaemia among elderly including both sexes constituting $37.68 \%$ of total anaemic patients. Microcytic hypochromic anemia constituted $31.88 \%$ followed by normocytic hypochromic anemia constituting $17.39 \%$.

Saurabh R Shrivastava et al noted [15] normocytic normochromic anemia in $69.8 \%$ cases followed by microcytic hypochromic in $11.6 \%$ followed by normocytic hypochromic in $8.25 \%$ including both sexes. Ania et al [21] observed most common pattern in males was normocytic $(83 \%)$ followed by microcytic anemia (14\%) as compared to females of which $80 \%$ were normocytic and $16 \%$ is microcytic. According to S. Amarneel et al [14] $41.6 \%$ males have normocytic normochromic pattern followed by $16.66 \%$ microcytic anaemia compared to females $33.33 \%$ normocytic normochromic and $20.0 \%$ microcytic.anemia.

Anemia in elderly may be seen in coexistence with other disease It is therefore essential that the treating physician is aware of the coexistence of anemia in elderly.

\section{Conclusion}

Anemia should never be accepted as consequence of normal ageing process and should be thoroughly investigated in geriatric age group. Study of various morphological patterns of anemia helps in guiding etiology of anemia and thus directing towards the further required investigations facilitating the choice and implementation of effective therapy.

Funding: Nil, Conflict of interest: None initiated, Permission from IRB: Yes

\section{References}

1. Bhasin A, Rao MY. Charecteristics of anemia in elderly: A hospital based study in south India. Indian journal of hematology and blood transfusion 2011; 27(1):26-32.

2. Hee-Seon Kim and Byung-Kook Lee. Cross-sectional study on the prevalence of anemia among rural elderly in Asan. Nutr Res Pract 2008; Spring; 2(1):8-12. 
3. Global Health and Ageing : National Institute on Aging, National Institute of Health, U. S. Department of Health and Human services, WHO

4. Ferrucci L, Semba RD, Guralnik JM et al. Proinflammatory state, hepcidin, and anemia in older persons. Blood. 2010 May 6;115(18):3810-6. doi: 10. 1182/ blood-2009-02-201087. Epub 2010 Jan 15.

5. World Health Organization. Definition of an older or elderly person. Retrieved August 29, 2010. http:// www.who.int/healthinfo/survey/ageingdefnolder/en/ind ex.html.

6. Helda Khusun, Ray Yip, Werner Schultink and Drupadi HS Dillon. World Health Organization Hemoglobin Cut-Off Points for the Detection of Anemia. Journal of Nutrition 1999; 129:1669-74.

7. WHO, UNICEF, and UNU, Iron Deficiency Anaemia: Assessment, Prevention and Control, A Guide for Programme Managers, WHO, UNICEF, UNU, Geneva, Switzerland, 2001, http:// www. who.int/nutrition/publications/micronutrients/anaemia iron deficiency/WHO NHD 01.3/en/index.html.

8. Tabea Geisel, JuliaMartin et al: An Etiologic Profile of Anemia in 405 Geriatric Patients, Hindawi Publishing Corporation Anemia Volume 2014, Article ID 932486, 7 pages.

9. E. A. Price, R. Mehra, T. H. Holmes, and S. L. Schrier. "Anemia in older persons: etiology and evaluation, "Blood Cells, Molecules, and Diseases, vol. 46, no. 2, pp. 159-165, 2011.

10. Guralnik Jack M, Eisenstaedt RS, Luigi Ferrucci. Prevalence of anemia in persons 65 years and older adults. Blood 2004; 104:2263-9.

11. World Health Organization. Definition of an older or elderly person. http: //who. int/ healthinfo/ survey/ agingdefnolder/en/index.html. Retrieved August 29, 2010 .
12. Benoist BD Mc Lean Erin, Egli Ines, Cogswell Mary. Worldwide prevalence of anemia. 1993-2005: WHO Global Database on Anemia. Spain: WHO, 2008

13. Stedman's medical dictionary (28th ed.). Philadelphia: Lippincott Williams \& Wilkins. 2006.p. Anemia. ISBN 9780781733908.

14. S. Amarneel and N. Sheth. Pattern of Anemia in Elderly Age Group IJSRR 2015, 4(2),51 - 56.

15. Saurabh R Shrivastava1*, Surekha B Hippargi1 Patterns of Anemia in Geriatric Age Group JKIMSU, Vol. 2, No. 1, Jan-June 2013.

16. Chernetsky A, Sofer O, Rafael C. Prevalence and etiology of anemia in an Institutionalized geriartic population. Harefuah, 2002; 141:591-4,667.

17. E. M. Inelmen, M. D'Alessio, M. R. A. Gatto et al., "Descriptive analysis of the prevalence of anemia in a randomly selected sample of elderly people living at home some results of an Italian multicentric study," Aging, vol. 6, no. 2, pp. 81-89, 1994.

18. M. E. Salive, J. Cornoni-Huntley, J. M. Guralnik et al., "Anemia and hemoglobin levels in older persons: relationship with age, gender, and health status," Journal of the American Geriatrics Society, vol. 40, no. 5, pp. 489-496, 1992.

19. R. Eisenstaedt, B. W. J. H. Penninx, and R. C. Woodman, "Anemia in the elderly: current understanding and emerging concepts," Blood Reviews, vol. 20, no. 4, pp. 213-226, 2006.

20. A.R. Nissenson, L. T. Goodnough, and R. W. Dubois, "Anemia: not just an innocent bystander?" Archives of Internal Medicine, vol. 163, no. 12, pp. 1400-1404, 2003.

21. Ania BJ, Suman VJ, Fairbanks VF.Incidence of anemia in older people: an Epidemiologic study in a well defined population. J Am Geriatric Soc 1997; 45: 825-31.

\section{How to cite this article?}

Singh R, Gaur B. S. Pattern of anemia in geriatric patients- A hospital based prospective study. Int J Med Res Rev 2016;4 (7):1250-1254.doi:10.17511/ijmrr.2016.i07.30. 